\title{
Autoradiography reveals regional metabolic differences in the endometrium of pregnant and nonpregnant mice
}

S.F. Oliveira,

P. Abrahamsohn and T.M.T. Zorn

\author{
Departamento de Histologia e Embriologia, Universidade de São Paulo, \\ São Paulo, SP, Brasil
}

\section{Correspondence \\ T.M.T. Zorn \\ Departamento de Histologia e \\ Embriologia, USP \\ Av. Lineu Prestes, 1524 \\ 05508-900 São Paulo, SP \\ Brasil \\ Fax: 55 (011) 818-7309 \\ E-mail: temtzorn@usp.br}

Presented at the 5th International Symposium on Radioautography, São Paulo, SP, Brasil,

August 24-26, 1997.

Publication supported by FAPESP.

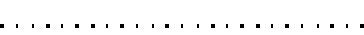

Received October 16, 1997 Accepted October 28, 1997

\section{Abstract}

The rodent endometrium undergoes remarkable modifications during pregnancy, resulting from a redifferentiation of its fibroblasts. During this modification (decidualization), the fibroblasts transform into large, polyhedral cells that establish intercellular junctions. Decidualization proceeds from the subepithelial stroma towards the deep stroma situated next to the myometrium and creates regions composed of cells in different stages of differentiation. We studied by autoradiography whether cells of these different regions have different levels of macromolecular synthesis. Radioactive amino acids or radioactive sulfate were administered to mice during estrus or on different days of pregnancy. The animals were killed $30 \mathrm{~min}$ after injection of the precursors and the uteri were processed for light microscope autoradiography. Silver grains were counted over cells of different regions of the endometrium and are reported as the number of silver grains per area. Higher levels of incorporation of amino acids were found in pregnant animals as compared to animals in estrus. In pregnant animals, the region of decidual cells or the region of fibroblasts transforming into decidual cells showed the highest levels of synthesis. Radioactive sulfate incorporation, on the other hand, was generally higher in nonpregnant animals. Animals without decidual cell transformation (nonpregnant and 4th day of pregnancy) showed a differential incorporation by subepithelial and deep stroma fibroblasts. This study shows that regional differences in synthetic activity exist in cells that are in different stages of transformation into decidual cells as well as in different regions of the endometrium of nonpregnant mice.

\section{Decidualization in rodents}

Decidualization is a very rare phenomenon in which differentiated cells (fibroblasts) redifferentiate under physiological conditions after exposure to a defined hormonal sequence and to a less specific triggering stimulus (for reviews, see Refs. 1-3). The transformed fi-

\section{Key words}

- Autoradiography

- $\left[{ }^{3} \mathrm{H}\right]$-Proline

- [ ${ }^{35}$ S]-Sulfate

- Endometrium

- Mouse

..................... broblasts are known as decidual cells and can be considered as a new cell type because of their modified morphology and acquisition of new synthetic capability. Decidualization occurs in the endometrium of several species of rodents as well as of humans.

Mouse decidual cells are large and polyhedral. Their nuclei are round and the nucleoli 
are prominent (4). Mouse decidual cells are often multinucleated. Their cytoplasm acquires a large amount of organelles associated with macromolecule synthesis and secretion as well as lysosomes (5). The accumulation of intermediate filaments is an important feature of rodent decidual cells (6). Although the endometrial fibroblasts have intermediate vimentin filaments, during transformation into decidual cells they acquire desmin filaments which are considered to be a marker of decidualization (7). Intercellular junctions, rarely present when decidual cells were fibroblasts, become profuse and occupy extensive areas of the cell surface (8). These junctions are mainly of two types, i.e., adherens and gap junctions (5). One of these junctions stains with anti-desmoplakin I/II antibody (9).

Several functions have been attributed to the mouse decidua, including nourishment of the embryo prior to development of the placenta, controlling penetration of the trophoblast and protection of the embryo from maternal immunoglobulins and migratory cells $(1,10,11)$. In rats the decidua has been shown to produce a luteotrophic factor with actions similar to those of prolactin (12). Recent morphological and immunocytochemical evidence has shown that prolactin is present in granules of a special subpopulation of cells of the mouse antimesometrial decidua (13). Human and mouse decidual cells were shown to continue producing collagen as they did before transformation $(14,15)$. Biochemical and immunochemical data have shown that mouse decidual cells secrete increasing amounts of type V collagen, a molecule that could not be detected in the nonpregnant endometrium (16).

The events of fibroblast transformation into decidual cells are now well known. During normal pregnancy in rodents, the exposure of endometrial fibroblasts to a sequence of estrogen secreted during proestrus, luteal progesterone and nidatory estrogen turns these cells sensitive to a stimulus pro- vided by the intimate contact between the implanting embryo and the uterine epithelium (17). The uterine epithelium is thought to transduce the stimulus into one or more messages to the subepithelial fibroblasts inducing them to transform into decidual cells (18). The main messenger is supposed to be a prostaglandin that is synthesized by the epithelial cells and later on also by the newly transformed decidual cells so that these cells influence surrounding fibroblasts to transform into new decidual cells $(19,20)$. Mouse decidual cells store phospholipids containing choline in their cytoplasm which is probably used as precursor for prostaglandin synthesis (21).

Thus, when a section of a mouse implantation site on the 5th day of pregnancy (dop) is analyzed with a light microscope, it is possible to visualize several regions of illdefined limits in the endometrium. The layer of subepithelial decidual cells that surround the implanting embryo represents the first fibroblasts that undergo redifferentiation and will be called mature decidual cells. These cells show the most advanced degree of morphological modification (5).

The mature decidual cells are surrounded by a population of fibroblasts that are in the process of redifferentiating into decidual cells, called predecidual cells. They retain intermediate features between the fibroblasts and mature decidual cells. Finally, in the deep endometrium, close to the myometrium, is a layer of nontransformed fibroblasts. From the 6th dop on, the cells that are closest to the embryo begin to involute and finally die (22). These involuting decidual cells become interposed between the embryo and the mature decidual cells.

A very interesting feature of decidualization in rodents, which reflects the way in which this reaction is induced, is the fact that decidualization is restricted to the endometrial areas that surround the implanting embryos (implantation sites). Areas farther away from the embryos (interimplantation sites) 
do not undergo any visible modification during decidualization.

In short, this morphological heterogeneity represents cells in several stages of redifferentiation and structural rearrangement with which different metabolic activities are probably associated.

\section{Autoradiographic studies}

To determine whether the various regions of the endometrium involving implantation sites have distinct metabolic rates, we examined by light microscope autoradiography the incorporation of three different radioactive precursors by endometrial stromal cells of pregnant mice as well as of mice in estrus so as to compare the metabolism of the endometrium of both groups. The tissues were fixed and embedded in paraffin or Epon. Sections were coated with Ilford K2 autoradiographic emulsion, developed with D19b, fixed and stained with hematoxylin/eosin or toluidine blue.

In pregnant animals, incorporation of the precursors was measured as the number of silver grains/cytoplasmic area in the following regions: a) mature decidual cells, b) cells transforming into decidual cells (predecidual cells), and c) nontransformed fibroblasts of the deep endometrium. In 6th dop animals incorporation was also analyzed in the decidual cells that directly surround the embryos and are beginning to involute. In virgin animals the concentration of silver grains was evaluated in the fibroblasts of the subepithelial and of the deep stroma.

The amino acid $\left[{ }^{3} \mathrm{H}\right]$-proline was injected into virgin mice and into mice on the 5th and 6 th dop. $\left[{ }^{3} \mathrm{H}\right]$-Tryptophan was injected into 6th dop mice. All animals were killed $30 \mathrm{~min}$ after the administration of the precursors.

The results of $\left[{ }^{3} \mathrm{H}\right]$-proline and $\left[{ }^{3} \mathrm{H}\right]$-tryptophan incorporation are shown in Figure 1. Incorporation of both precursors was highest in decidualized areas of pregnant endometria. On the other hand, lower levels of

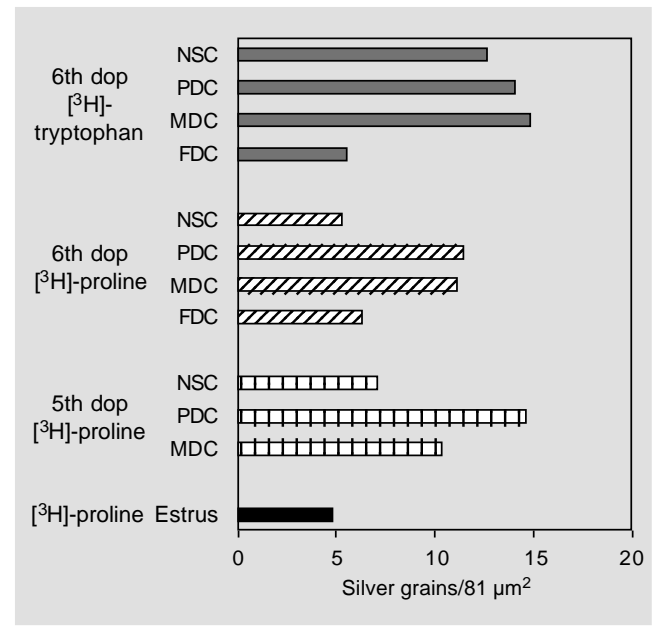

Figure 1 - Incorporation of $\left[{ }^{3} \mathrm{H}\right]-$ proline or $\left[{ }^{3} \mathrm{H}\right]$-tryptophan by mouse endometrial stromal cells during estrus and on the 5th and 6 th days of pregnancy (dop). The bars represent the average of silver grain counts per $81 \mu^{2}$. MDC: Mature decidual cells; PDC: predecidual cells; NSC: nondecidualized stroma cells; FDC: flattened decidual cells. incorporation were observed in the endometrium of virgin animals as well as in areas of pregnant endometrium not involved with decidualization (the deep stroma). Decidual cells that were already undergoing involution as part of their natural cycle (flattened decidual cells) also showed low levels of amino acid incorporation.

A special experiment was performed on mice injected with high specific activity proline. The animals were killed 1, 2 and $24 \mathrm{~h}$ later and tissues were prepared for electron microscope autoradiography (15).

At 1 and $2 \mathrm{~h}$ the incorporation of $\left[{ }^{3} \mathrm{H}\right]-$ proline was mainly intracellular, concentrated over the endoplasmic reticulum and Golgi cisternae. At $2 \mathrm{~h}$ some silver grains were also present in the extracellular matrix. At $24 \mathrm{~h}$ most silver grains were concentrated over collagen fibrils. These results indicate that most of $\left[{ }^{3} \mathrm{H}\right]$-proline was incorporated to synthesize new collagen.

Radioactive sulfate is known to be incorporated into sulfated glycosaminoglycans (23). Radioactive sulfate in the form of $\mathrm{Na}_{2}{ }^{35} \mathrm{SO}_{4}$ was injected into virgin mice and into 4th, 5th and 6th dop mice and the animals were killed $6 \mathrm{~h}$ after the injection.

Counting of silver grains over the endometrial stromal cells revealed that their concentration was highest in virgin animals and declined in pregnant animals (Figure 2).

In virgin animals the incorporation was 
Figure 2 - Incorporation of ${ }^{35} \mathrm{~S}$ by mouse endometrial stromal cells during estrus and on days 4,5 and 6 of pregnancy (dop). In nonpregnant mice and 4-day pregnant animals the silver grains were counted over cells of the subepithelial region (SE) and of the deep stroma (DS) of the endometrium. At implantation sites the grains were counted over flattened decidual cells (FDC), mature decidual cells (MDC), predecidual cells (PDC), and nondecidualized stroma cells (NSC). The bars represent the average of silver grain counts per $1,000 \mu \mathrm{m}^{2}$.

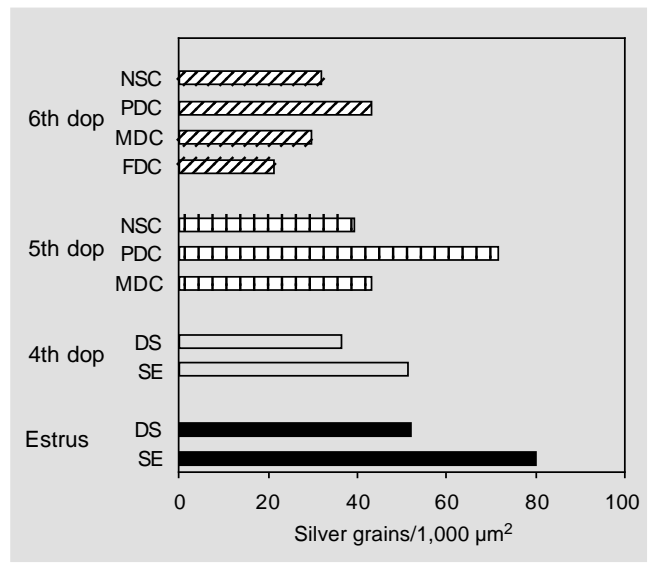

higher in the subepithelial region than in the deep stroma. Similarly, on the 4th dop, before overt decidualization started, incorporation was higher in the subepithelial stroma. On days 5 and 6 the incorporation was highest in predecidual cells.

Endometrial regions situated between implanting embryos (interimplantation sites) and that do not undergo modifications during pregnancy showed incorporation levels similar to those of the nondecidualized deep stroma (data not shown).

A parallel ultrastructural study was performed to investigate the fundamental matrix of the endometrium during pregnancy. With the use of cationic dyes (safranine O, ruthenium red, ruthenium hexamine trichloride) added to the fixatives used during preparation of tissues for electron microscopy, the proteoglycans become much better preserved than with aldehydes alone (24-26). With this treatment the proteoglycans of the extracellular matrix appear as networks of filaments and/or granules. The arrangement of these networks, their density and the size of their meshes are different in the several regions of the endometrium in pregnant mice. Interestingly, even in virgin mice and in preimplantation uteri the features of the proteoglycan network are different when the subepithelial stroma and the deep stroma are compared (Grecca PS, personal communication).

\section{Comments}

Decidualization in rodents offers a good opportunity to study a system in which redifferentiation occurs in normal adult mammals.

Previous biochemical data from our laboratory have shown different levels of synthesis of sulfated glycosaminoglycans in the endometrium during various stages of pregnancy in the mouse (27). Since the decidua has cells in different stages of transformation, the use of an in situ approach such as autoradiography is a better choice over biochemical techniques because, instead of analyzing the tissue as a whole, it permits the detection of regional differences within a tissue.

The autoradiographic results show that at implantation sites the endometrial regions which can be distinguished by morphological characteristics also have different metabolic activity.

The regions found to be metabolically more active are those in which the cells are growing more intensively (predecidual cells) or synthesizing more actively (mature decidual cells). On the other hand, involuting decidual cells and nontransformed cells in the deep stroma had the lowest incorporation of radioactive precursors.

One of the rare autoradiographic studies on amino acid incorporation by decidual cells was performed in rats by Takekida (28). This author observed that the incorporation of $\left[{ }^{3} \mathrm{H}\right]$-methionine was lower around the embryo than in areas farther away. These areas are probably equivalent to the regions of flattened decidual cells and mature decidual cells and thus his results are similar to ours.

An important result of our study was that subepithelial and deep stromal cells of nonpregnant endometria also behaved differently, with the former being more active. 
Several questions must be addressed concerning the meaning of regionalization: Are there ovarian hormone receptors in both subepithelial and deep stroma cells in nonpregnant animals? Would cells of both regions be capable of transforming into decidual cells if properly stimulated? Or does regionalization result solely from the way in which the stimulus is applied, i.e., in a centrifugal direction from the epithelium toward the myometrium? In this case, is it feasible to assume that the decidualizing stimulus does not have enough time to reach the deep endometrium before decidual involution?

On the other hand, the finding that subepithelial cells are more active in nonpregnant endometria may be very important for the understanding of uterine physiology. This may indicate that there are at least two cell populations in the nonpregnant mouse endometrium. The subepithelial cells would be committed to a functional role such as sustaining the developing embryo. The deep endometrial cells, on the other hand, are known to regenerate the endometrium during the postpartum period (29) and probably stay quiescent during the sexual cycles and pregnancy. The organization of the mouse endometrium is thus similar to that of the human endometrium where a subepithelial functional layer undergoes profound modifications during the menstrual cycle while the deep, basal layer acts to rebuild the endometrium after menstruation.

\section{References}

1. Finn CA (1977). The implantation reaction. In: Wynn RM (Editor), Biology of the Uterus. Plenum Press, New York.

2. Parr MB \& Parr EL (1989). The implantation reaction. In: Wynn RM \& Jollie WP (Editors), Biology of the Uterus. Plenum Publishing Corporation, New York.

3. Abrahamsohn PA \& Zorn TMT (1993). Implantation and decidualization in rodents. Journal of Experimental Zoology, 266: 603-628.

4. Lundkvist O (1978). Ultrastructural studies of the endometrial stromal cells in rats during estradiol-induced implantation after an experimental delay. Biology of Reproduction, 18: 306-316.

5. Abrahamsohn PA (1983). Ultrastructural study of the mouse antimesometrial decidua. Anatomy and Embryology, 166: 263-274.

6. Zorn TMT, Oliveira SF \& Abrahamsohn PA (1990). Organization of intermediate filaments and their association with collagencontaining phagosomes in mouse decidual cells. Journal of Structural Biology, 103: 23-33.

7. Glasser SR \& Julian JA (1986). Intermediate filament protein as a marker for uterine stromal cell decidualization. Biology of Reproduction, 35: 463-474.

8. Finn CA \& Lawn AM (1967). Specialized junctions between decidual cells in the uterus of the pregnant mouse. Journal of Ultrastructural Research, 20: 321-327.
9. Andrade CGTJ, Savino W, Abrahamsohn PA \& Zorn TMT (1994). Distribution of desmoplakin $\mathrm{I} / \mathrm{II}$ in endometrial cells of mice in the artificially induced decidua. Tissue and Cell, 26: 639-647.

10. Parr MB \& Parr EL (1986). Permeability of the primary decidual zone in the rat uterus: studies using fluorescein-labeled proteins and dextrans. Biology of Reproduction, 34: 393-403.

11. Lino da Costa G (1991). Migration of leukocytes in the decidualized endometrium of pseudopregnant rats. Doctoral thesis, Instituto de Ciências Biomédicas, Universidade de São Paulo, São Paulo, SP.

12. Gibori G, Rothchild I, Pepe GJ, Morishige WK \& Lam P (1974). Luteotrophic action of decidual tissue in the rat. Endocrinology, 95: 1113-1118.

13. Monice FL, Pellegrini CMR, Campos KO, Abrahamsohn PA \& Zorn TMT (1997). Immunocytochemical detection of prolactin in granulated decidual cells of pseudopregnant mice. Brazilian Journal of Morphological Sciences, 14: 125 (Abstract).

14. Kisalus LL, Herr JC \& Little CD (1987). Immunolocalization of extracellular matrix proteins and collagen synthesis in firsttrimester human decidua. Anatomical Record, 218: 402-415.
15. Oliveira SF, Nagata T, Abrahamsohn PA \& Zorn TMT (1991). Electron microscopic radioautographic study on the incorporation of $3 \mathrm{H}$-proline by mouse decidual cells. Cellular and Molecular Biology, 37: 315323.

16. Teodoro WR, Shimokomaki M, Abrahamsohn PA \& Zorn TMT (1994). Characterization of collagen types of pregnant mouse endometrium. 3rd Brazilian Symposium on Extracellular Matrix. Angra dos Reis, 126 (Abstract).

17. Finn CA \& Martin L (1972). Endocrine control of the timing of endometrial sensitivity to a decidual stimulus. Biology of Reproduction, 7: 82-86.

18. Lejeune B, Van Hoeck J \& Leroy F (1981). Transmitter role of the luminal uterine epithelium in the induction of decidualization in rats. Journal of Reproduction and Fertility, 61: 235-240.

19. Parr MB, Parr EL, Munaretto K, Clark MR \& Dey SK (1988). Immunohistochemical localization of prostaglandin synthase in the rat uterus and embryo during the periimplantation period. Biology of Reproduction, 38: 333-343.

20. Kennedy TG, Squires PM \& Yee GM (1989). Mediators involved in decidualization. In: Yoshinaga $\mathrm{K}$ (Editor), Blastocyst Implantation. Adams Publishing Group, Ltd., Boston. 
21. Alberto-Rincon MC, Paiva CS, Abrahamsohn PA \& Zorn TMT (1994). Histochemical demonstration of phospholipid containing choline in the cytoplasm of murine decidual cells. Acta Anatomica, 150: 119126.

22. Katz S \& Abrahamsohn PA (1987). Involution of the antimesometrial decidua in the mouse. Anatomy and Embryology, 176: 251-258.

23. Fatemi SH \& Leblond CP (1985). Sulfatation and transport of basement membrane proteoglycans, as visualized by ${ }^{35} \mathrm{~S}$ sulfate radioautography in the endodermal cells of the rat parietal yolk sac. American Journal of Anatomy, 173: 127145.
24. Hunziker EB, Hermann RK \& Schenk RK (1982). Improved cartilage fixation by ruthenium hexamine trichloride (RHT). A prerequisite for morphometry in growth cartilage. Journal of Ultrastructural Research, 81: 1-12.

25. Rosenberg $L$ (1982). Chemical basis for the histological use of safranin $O$ in the study of articular cartilage. Journal of Bone and Joint Surgery, 53: 69-74.

26. Wight TN \& Hascall VC (1983). Proteoglycans in primate arteries. III. Characterization of the proteoglycans synthesized by arterial smooth muscle cells in culture. Journal of Cell Biology, 96: 167-176.
27. Zorn TMT, Pinhal MAS, Nader HB, Carvalho JJ, Abrahamsohn PA \& Dietrich CP (1995). Biosynthesis of glycosaminoglycans in the endometrium during the initial stages of pregnancy of the mouse. Cellular and Molecular Biology, 41: 97106.

28. Takekida H (1971). Autoradiographic studies on the nucleic acid and protein synthesis and the decidualization of endometrium in early pregnancy of rat. Acta $\mathrm{Ob}$ stetrica et Gynaecologica Japonica, 18: 200-213.

29. Kleinfeld RG \& O'Shea JD (1983). Spatial and temporal patterns of deoxyribonucleic acid synthesis and mitosis in the endometrial stroma during decidualization in the pseudopregnant rat. Biology of Reproduction, 28: 691-702. 